\title{
Allocation Code
}

National Cancer Institute

\section{Source}

National Cancer Institute. Allocation Code. NCI Thesaurus. Code C93503.

A coded value specifying the method of assigning entities to groups or categories. 